Territorios 35 / Bogotá, 2016, pp. 37-57

ISSN: 0123-8418

ISSNe: 2215-7484

La fase actual del capitalismo y la urbanización en América Latina (II)

\title{
Discursos, política y poder: el espacio público en cuestión
}

Discourses, Politics and Power: Public Space in Question

Discursos, política e poder: o espaço público em questão

\author{
Carla Alexandra Filipe Narciso* \\ Blanca Rebeca Ramírez Velázquez ${ }^{\star *}$
}

Recibido: 18 de enero de 2016

Aprobado: 26 de abril de 2016

Doi: dx.doi.org/10.12804/territ35.2016.02

Para citar este artículo:

Filipe, C. \& Ramírez, B. (2016). Discursos, política y poder: el espacio público en cuestión. Territorios, 35, 37 57. Doi: dx.doi.org/10.12804/territ35.2016.02

\begin{abstract}
* Doctora en Urbanismo de la Universidad Nacional Autónoma de México, UNAM. Profesora de la Universidad Nacional Autónoma de México. Correo electrónico: carla-narciso@ iol.pt

** Doctora en Urbanismo de la Universidad Nacional Autónoma de México, UNAM. Profesora-Investigadora de la Universidad Autónoma Metropolitana -Xochimilco. Correo electrónico: blare19@me.net. $m x$
\end{abstract}


Palabras clave

espacio público, politicas de intervención, prácticas sociales, función urbana, derecho a la ciudad.

Keywords

Public space, Public interventions, Social practices, Urban function, Right to the city.

Palavras-chave espaço público, políticas de intervenção, práticas sociais, função urbana, direito à cidade.

\section{territarias 35}

\section{RESUMEN}

Como resultado de una investigación profunda sobre el sentido, las prácticas, la percepción y la política del Estado en el espacio público de la ciudad de Cuernavaca, México, se desarrollan unas reflexiones teóricas, tal y como se solicitó en la convocatoria al $2^{\circ}$ Seminario de la Red Latinoamericana sobre Teoría Urbana, relacionadas con el significado del concepto de espacio público y su función dentro de la ciudad; así también se cuestiona el cometido que se le ha dado de ser un instrumento que genera ciudadanía, elimina la exclusión y controla el desarraigo, como partes fundamentales del cuestionamiento que se hace al llamado "derecho a la ciudad".

\section{ABSTRACT}

As a result of a deep research regarding the sense, practices, use, perception and public intervention in public space in Cuernavaca, Morelos, México, theoretical reflections were issued answering the call of papers of the $2^{\text {nd }}$ Seminar of the red Lationamericana sobre Teoria Urbana in relation to the concept of public space and the function it has within the city. A criticism is made considering public space as a tool for the construction of citizenship and control of exclusion as fundamental parts of the questioning done to the called 'right to the city'.

\section{RESUMO}

Como resultado de uma pesquisa profunda sobre o sentido, as práticas, a percepção e a política do Estado no espaço público da cidade de Cuernavaca, México, se desenvolvem umas reflexões teóricas, tal como se solicitou na convocatória ao $2^{\circ}$ Seminário da Rede Latino-Americana sobre Teoria Urbana, relacionadas com o significado do conceito de espaço público e a sua função dentro da cidade; assim também se questiona o papel que se lhe tem dado de ser um instrumento que gera cidadania, elimina a exclusão e controla o desarraigo, como partes fundamentais do questionamento que se faz ao chamado "direito à cidade". 


\section{Introducción: las bases empíricas de la reflexión teórica}

La globalización y su política manifiesta: el neoliberalismo ha impulsado en las últimas décadas un urbanismo que adapta la construcción de la ciudad y las nuevas formas urbanas a la fragmentación y dispersión mediante la compresión del espaciotiempo, que el capitalismo tardío impulsó a través de la aceleración de los procesos económicos, la creciente mercantilización de la vivienda, los símbolos culturales y la transformación de la experiencia subjetiva de su producción y reproducción (Harvey, 2004). En este contexto, se han desarrollado mutaciones importantes en los procesos de reproducción social de la ciudad, en una recomposición social o bien en una parcelación y separación más aguda de las clases y los grupos que la conforman.

En la actualidad, se han empezado a cuestionar las funciones de los espacios urbanos con el argumento de que el espacio propio del urbanismo moderno perdía protagonismo e importancia frente al espacio de flujos que impulsó el urbanismo posmoderno, donde todo se mueve y nada se fija. El resultado, se aducía, era la pérdida de espacios de convivencia, sociabilidad, encuentro, recreación e identidad $\mathrm{y}$, en consecuencia, se generó una mayor segregación y exclusión social. Para esta línea de pensamiento, el concepto de espacio público tuvo un lugar destacado, ya que no solo se le consideró como un elemento físico constitutivo de la trama urbana, sino que también se consideró como un instrumento político que contribuía a la cohesión social y a la integración de los sectores excluidos o vulnerables, capaz de contrarrestar la incontrolable fluidez y el desarraigo territorial del capitalismo tardío (Bauman, 2005; Castells, 1996), dar empleo y desarrollo económico (Segovia \& Jordan, 2005), y además, al acceder a él, se alcanzaría lo que se ha denominado el derecho a la ciudad (Carrion, 2007; Borja \& Forn, 1996).

Esta idealización del espacio público, originada e importada de la filosofía política (Narciso, 2014), ha sido vital en los estudios urbanos, y ha reproducido modelos "demasiado encorsetados en una previsible y aburrida red de oposiciones binarias" (Estévez, 2012), como público-privado y se convirtió en la base hegemónica de los discursos políticos y académicos contemporáneos; evidentemente el trabajo de investigación partió de la necesidad de realizar una revisión bibliográfica sobre el tema que queda integrada en el documento de Narciso (2014).

Cuando quisimos comprobar estos supuestos en el espacio público específico de Cuernavaca, localizada a una hora de la Ciudad de México, a partir de un análisis concreto que llevara a ejemplificar estos procesos en el estudio de caso, nos encontramos lo contrario (Narciso, 2014). Un trabajo de investigación de más de dos años que tuvo como objetivo reconceptuar, a partir de la forma como se construyen, apropian y usan los espacios públicos en la ciudad, nos llevó a conclusiones empíricas contrarias a las que los supuestos manejaban sobre estos espacios. A partir de un territarios 35 
${ }^{1}$ Estos documentos son de trabajo e inéditos por lo que no ban sido publicadosy por ende no es posible citarlos.

\section{territarias 35}

estudio detallado de la tipología de los espacios públicos de la ciudad, se identificaron los conceptos definidos por diferentes agencias estatales o privadas; esta se obtuvo de la recolección de información oficial que se encuentra solo en los archivos de la ciudad, en un reconocimiento de usos del suelo y en el conocimiento de los funcionarios públicos, lo cual permitió identificar los diferentes espacios públicos ${ }^{1}$.

La profundización del uso, transformación y apropiación de esta investigación se llevó a cabo en tres lugares concretos: La Plazuela del Zacate, el parque CRI CRI y el Centro Comercial de Galerías. En cada uno se trabajó cualitativamente con 80 entrevistas semiestructuradas (240 en total) y con observación participante durante siete días de la semana en diferentes horarios (mañana, medio día y noche), que permitieron acercarnos a una experiencia de lo cotidiano de los diferentes agentes que los usaban, apropiaban, transformaban o percibían. Encontramos tres formas de espacio público correspondientes a los antes mencionados: la primera, como parte del centro histórico de la ciudad, que servía de paso para las funciones públicas y de esparcimiento de jóvenes en las noches o los fines de semana; la segunda, como lugar de borde de las zonas del mercado central de la ciudad que permitía la recreación de las clases populares o la obtención de trabajo de plomeros, albañiles u otras especialidades; la tercera, forma parte de los nuevos centros comerciales neoliberales que han proliferado como lugares de recreo y esparcimiento de las clases sociales acomodadas.
Así, el análisis empírico y teórico realizado permitió concluir que, a diferencia de lo que se concibe, en realidad el espacio público presenta un uso fragmentado que se constituye como diferenciador social más que como integrador o cohesionador. De acuerdo con nuestro punto de vista, estamos frente a una construcción ideológica diferente a la definición de un espacio como un contenedor homogéneo, que se aplica y explica en todos los lugares de la misma forma o "una práctica entendida como una unidad o incluso como una política dominada por una misma perspectiva" (Delgado, 2011, p. 10). Esta discusión quedó integrada en la primera parte del artículo; en ella se analizan los diferentes conceptos que se tienen del espacio público: se hace una reflexión sobre las razones para categorizarlo como carente de significado e ideologizado. En la segunda, argumentamos que la fragmentación social y la reproducción de clase de los espacios públicos llevan a un mercantilismo urbano que dista mucho de dar las condiciones para generar un derecho a la ciudad. En la tercera, se analizan las bases con las que Lefebvre (1973) construyó su postura en relación con el derecho a la ciudad que no corresponde a la de la ciudad mercantilista, sino a la que promueve la ONU Hábitat, e incluso algunos gobiernos de izquierda de América Latina. Estos hallazgos nos han permitido poner en duda la utilidad que tiene actualmente el uso del derecho a la ciudad como instrumento para generar cohesión social y ciudadanía. 


\section{Un concepto carente de significado}

Las ciudades en América Latina se transforman y se resignifican muy rápidamente, por lo que un espacio público, un público, una opinión pública o hasta un servicio o bien público son cosas que ciertamente cambian de forma muy "natural" y, al mismo tiempo, muy objetiva, a partir de las determinantes políticas, ideológicas, sociales y culturales que dictan las transformaciones de la ciudad (Narciso, 2014). Hablar hoy de espacio público es hablar de un concepto polisémico y altamente cambiante e idealizado, que puede tener múltiples significados dependiendo del autor y del momento en que se construyó, pero al mismo tiempo es un concepto en donde se incluye a toda la ciudad, excepto la vivienda que es privada.

Como componente ideológico primordial de lo urbano, el uso del concepto de espacio público se convierte en un elemento de discusión en los estudios urbanos a partir de los años setenta, al interior de las ciencias sociales, destacando la sociología, la geografía, la antropología y el urbanismo, al ser tomado este como un componente urbano capaz de sostener o desencadenar otros procesos económicos y culturales (Portas, 2003); al mismo tiempo, es un elemento que "supuestamente" permite entender la metrópoli contemporánea $(\mathrm{Du}-$ hau \& Giglia, 2008) a partir del análisis de su uso, forma y estructura.

Las discusiones que actualmente se despliegan de forma persistente en el es- tudio del espacio público, sin embargo, se han desarrollado al margen de una conceptualización práctica o de un abordaje del lugar y de las relaciones de poder que en él se desarrollan, y se asume como una realidad dada, incuestionable, es decir, como un espacio absoluto. El vacío de sentido y significado que se concretiza a partir de realidades arbitrarias heredadas de la modernidad, pero que lo identifica en la actualidad como algo que es capaz de regenerar, integrar y disolver las diferencias sociales, se ve interrumpida por el neoliberalismo, perdiendo su condición de libre acceso e igualdad, ganando nuevos significados, a través de nuevas formas urbanas.

Pero ¿qué significado tiene realmente el concepto de espacio público? Responder esta pregunta es un tanto complejo, ya que el resultado de nuestra investigación muestra que hay tantos espacios públicos como realidades existentes; de hecho, hoy más que nunca los significados desde una concepción instrumental son múltiples y cada quien hace un uso del concepto de acuerdo con las necesidades que persigue. Esto fue claro en el trabajo de campo, en el cual no existe un solo espacio que se comporte de una forma similar, porque esto depende de las prácticas cotidianas de clase de los grupos que se lo apropian o usan.

La construcción del espacio público en la ciudad de Cuernavaca y las especificidades que ahí encontramos nos han permitido entender e interpretar a escala local los diversos significados que adquieren dichos espacios, pero también verlos como dimensiones cambiantes, ya que las territarias 35 
transformaciones socioeconómicas por las cuales ha pasado, redefinen sus funciones y las percepciones que los habitantes tienen de estos. El tema adquiere mayor relevancia cuando se asocia con las formas diferenciadas de uso y de apropiación que tienen los lugares, la calidad física y relacional del entorno construido, las prácticas sociales que en ellos se desarrollan, las formas organizativas de los agentes que los usan y transforman así como con la oferta cultural que ahí se promueven (Ramírez Kuri, 2009). Por ello, consideramos relevante, en una aproximación y razonamiento relacional, analizar los elementos físicos, institucionales, así como los programas y políticas de intervención, destacando sus objetivos, limitaciones y contradicciones que permiten comprehender las formas materiales e inmateriales que adopta el espacio público a diferentes escalas.

$\mathrm{Al}$ adentramos en las diferentes tipologías de los espacios públicos de Cuernavaca, encontramos contradicciones dadas por las calidades inherentes en cada una de ellas. Se identifican como espacios públicos a partir de criterios preestablecidos, encargados de hacer su intervención, desarrollo o manutención; se consideraban en un mismo nivel distintos tipos de espacio como parques, jardines, plazas, camellones, aceras, calles, fuentes, áreas verdes, jardineras, glorietas o unidades deportivas. Esta identificación fue importante para conocer los espacios existentes, su cuantía y distribución al interior de la ciudad, su estado físico actual y su evolución en el tiempo, así como la intervención que hacen las diferentes ins- tituciones de gobierno para mantenerlos, mejorarlos o cambiarles su imagen y las contradicciones existentes en estas. También permitió observar la vivencia que los ciudadanos hacen de ellos, las conexiones y las relaciones existentes entre los diferentes grupos sociales que las usan y su vinculación con las instituciones.

Con el análisis histórico conocimos los principales espacios públicos de Cuernavaca en su formación. Cuando decimos principales, nos referimos a los que se identificaron de acuerdo con la conformación y crecimiento de la ciudad y con los distintos momentos que marcaron su configuración territorial y su tipología (plaza, jardín, parque). La vivencia de la ciudad evidenció, sin embargo, que había en el momento del estudio un mayor número de espacios públicos, aunque pudieran no tener la expresión y representatividad de los que acreditamos anteriormente, ya que muchos de ellos no tenían una centralidad histórica o dimensiones "visibles". Esto se pudo confirmar a partir de los levantamientos efectuados por los gobiernos municipal y estatal, pero mostraron una incongruencia y falta de información que fuera correspondiente con el levantamiento de campo.

El hecho de tener actores institucionales que intervienen el territorio de manera aislada provoca disparidades en la información, pero también en la forma, función y estructura del espacio público, que además está directamente involucrada con los agentes privados. Al mismo tiempo parece haber una contradicción, ya que el espacio público no es un elemento prioritario en 
las agendas políticas, solo en los discursos. Observamos es que la intervención institucional no sigue planes o programas determinados, sino políticas de mitigación y adaptación al contexto existente, asociadas con una lógica de mercado neoliberal, patente en las recientes intervenciones del ayuntamiento denominadas de "Embellecimiento del Paisaje Urbano de Cuernavaca".

Cabe igualmente destacar y promover la hipótesis de que existe una visión reduccionista en la intervención del espacio público, evidenciada en el propio concepto, confundido con áreas verdes o equipamientos donde este programa ha intervenido (camellones, aceras, glorietas); estos, aunque sean públicos, no permiten el recreo, la realización de actividades, la interacción social debido, en parte, a su tipología. Tampoco mejoran la calidad del ambiente urbano, porque son espacios muy puntuales y dispersos, y áreas muy pequeñas, pero que corresponden al imaginario de las clases pudientes de la ciudad, así como de la clase política, que ve estas intervenciones como una forma de atraer inversión nacional y extranjera.

Las estrategias de intervención de los gobiernos, así como del sector privado van determinando los agentes que usan los espacios, en lo cual la clase social es un elemento que territorializa los lugares. Los espacios públicos tradicionales, como es la plaza, el parque y el jardín, son utilizados en su gran mayoría por las clases populares, es el caso del Zócalo de Cuernavaca, el Jardín Juárez y el Jardín de San Juan, que son de propiedad pública, a los cuales no se da una atención, a no ser que exista una demanda política. Las clases altas, aunque reivindiquen aparentemente espacios públicos o de propiedad pública acorde con sus imaginarios colectivos, no dejan de ser meras intervenciones estéticas, porque los espacios públicos de su cotidianeidad son los espacios privados de uso público, como los centros comerciales y los clubes. Esa conciencia de clase es de tal forma intrínseca a la misma condición que no existe una transposición de fronteras (simbólicas y sociales) entre los mismos espacios, pero eso como un elemento natural de la misma historia del espacio público.

Nos parece limitado pensar que las posibilidades de existencia de un espacio público que es de todos, como un derecho, sea un elemento heredado de la modernidad y que el neoliberalismo lo haya terminado. En realidad nunca fue de todos, solamente de las clases hegemónicas, las cuales se han reproducido a lo largo de la historia a través de nuevas formas y políticas urbanas, así como de la intervención privada, esto no ha hecho más que acentuar las diferencias sociales entre los grupos urbanos.

\section{La función del espacio público}

Si el concepto de espacio público es idealizado por la modernidad, también lo es su función social, ya que esta se sigue manejando y reproduciendo a partir de objetivos contrarios a los que el discurso de su origen marca. En las grandes ciudades contemporáneas, el espacio público se ha convertido en el resultado de un urbanismo 
espectacular, ostentado en obras magnificentes que procuran incorporarlas en el mercado global, atraer inversión y obedecer a los imaginarios idílicos de las clases medias y altas. Con ello se deja en el olvido el espacio público de las clases populares que se reproduce desde la lógica del uso que ellas hacen de él, sin apoyo económico ni gubernamental ni privado.

Se debe evidenciar que, si bien con elementos de desarrollo homogeneizantes este tipo de urbanismo espectacular, a pesar de que sea un principio central en la planeación urbana, ha tomado diferentes direcciones en Europa o América Latina, pues la forma y la escala con la que se han implementado han sido distintas. En el caso de ciudades medias, como la de Cuernavaca, las intervenciones no son de índole espectacular, sino arreglos paisajísticos, sobre todo en las áreas de ingresos medios/ altos, que no se integran en los planes de desarrollo urbano o proyectos específicos. Otra forma de expresión de este tipo de urbanismo fue la proliferación de espacios comerciales, tipo centros comerciales y grandes plazas, que se han convertido en espacios públicos a pesar de ser privados, que han sido motivo de estudio de diversos académicos, quienes han puesto atención en las consecuencias urbanas y culturales que estos tienen (Caprón, 1997; Cornejo, 2006, 2007; Hiernaux, 2000; López Levi, 1997; Ramírez Kuri, 1993).

Cuando hablamos de un ejemplo de espacio público de la modernidad en la Ciudad de Cuernavaca (a finales del siglo territarias 35 44 a un espacio construido por las clases hegemónicas para su usufructo, a partir de las tipologías tradicionales como el jardín, la plaza y el parque que cumplen las funciones de recreo, esparcimiento, ver y ser visto, de encuentro entre agentes de igual condición o clase social, marcadamente homogéneos en intereses, gustos, expresiones y tradiciones culturales. En ellos, las clases bajas no tenían cabida y los espacios destinados a estas cumplían con funciones diferentes de las de clase alta, lo que permite cuestionar, desde entonces, la existencia de un espacio público de integración social o, incluso, de un espacio público como tal.

Autores como Sennett (1978) ya tejían esta crítica al espacio público de la modernidad (en sí), cuyas intervenciones denotaban más el proceso de diferenciación social, con lo cual el autor ya preveía la tan aclamada muerte del espacio público. En este sentido, los discursos actuales de una muerte o crisis del espacio público (Borja, 2005), deben ser revisados, ya que los mismos apuntan que esa muerte es consecuencia de una política neoliberal de privatización del espacio, que se puede evidenciar sobre todo en centros comerciales y condominios privados que destruyen los lazos de sociabilidad y ciudadanía. Retomando a Sennett (1978), lo que resultó de nuestra investigación es que antes del neoliberalismo el espacio público ya había muerto, porque lo limitaban a ciertos grupos o clases sociales, por lo cual era selectivo y fragmentario del territorio.

En Cuernavaca, el espacio público traXIX, principios del siglo XX) nos referimos dicional de la modernidad era para las clases 
hegemónicas, las cuales con la revolución de 1910 trasladaron las funciones tradicionales de los espacios públicos al ámbito privado - como el jardín de la casa o el club- mucho antes de que surgieran los centros comerciales. El neoliberalismo del siglo XX indujo un nuevo análisis al espacio público a partir de los centros comerciales, de la resignificación de los tradicionales como son los jardines privados o de otros políticamente estratégicos que promueven a una forma de control social, dependiendo de la clase que los use: puede ser de recreo y trabajo para clases bajas, como el parque CRI CRI que estudiamos o una construcción idílica de embellecimiento de los camellones de sus colonias para las clases medias o altas.

En la actualidad, el espacio público se convirtió en categoría de moda de los gobiernos locales y estales sobre todo en América Latina: es sinónimo de inversión y captación de fondos del sector privado, lo que define Harvey (1989) como empresarialismo urbano; su organización y transformación es muy similar a la que se tuvo en la modernidad, ya que ha redundado en un incremento de las diferencias sociales en las ciudades. Esta nueva forma de construir ciudad y espacio público, a partir del desarrollo del sector privado mediante sus empresas más que de la intervención pública directa del Estado, ha aumentado el número de condominios cerrados, la expansión de los centros comerciales y una imagen de intolerancia para el uso de ciertos grupos de estos espacios públicos. De ahí que el modelo se impone homogenei- zando a la ciudad a partir de la visión empresarial y de uso privado aun de espacios públicos. No se ofrecen soluciones reales para los problemas que las ciudades tienen, por el contrario, se imponen las soluciones que benefician el uso urbano para las clases media y alta. Harvey (1989) y Brenner \& Theodore (2002) critican este nuevo urbanismo como una forma de acumulación de capital, que siguen reproduciendo los mismos ideales de las propuestas de Haussaman, beneficiando a las clases altas y medias, pero no así a los desposeídos.

¿Qué es lo que actualmente hace la diferencia en el proceso de reproducción social del espacio público en el tiempo? Las representaciones del espacio definidas por Lefevbre (1991), asociadas a una racionalidad técnica y mercantil de quien lo construye, que no son en forma alguna neutrales, ya que están vinculadas con las instituciones de poder dominante y con las representaciones generadas por una "lógica de visualización" hegemónica, lo que da como resultado: nuevas formas urbanas, como centros comerciales asociados a la reproducción del capital, nuevas experiencias e imaginarios urbanos elitistas que las acompañan.

En el proceso de reproducción del espacio público, el Estado dispone de los gobiernos locales como actores directos e indirectos para producir en la ciudad una diferenciación social y una jerarquización de lugares, "[...] creando nuevas centralidades y expulsando para la periferia los antiguos habitantes, estableciendo un espacio de dominación" (Carlos, 2001, p. 15). Al 
delegar a los municipios la transformación y construcción de los espacios públicos, estos se aprovechan y, conscientes de sus limitantes, muestran y mezclan intereses públicos y privados, que van desde los del propio presidente municipal o de cualquier funcionario público responsable, hasta los de agentes privados, y grupos sociales hegemónicos, que en ocasiones entran en conflicto con los del resto de la población.

El conflicto se genera porque posiciona intereses contradictorios en donde gana el que más puede o el que más tiene. Así, el espacio público se usa como un instrumento político intencionalmente organizado y manipulado por las clases hegemónicas sean públicas o privadas, y es ahí donde se reflejan las tensiones por parte de los agentes que lo disputan, dependiendo de que la administración municipal quiera dejar su impronta y usarlo como moneda de cambio para fines electorales (un producto personalizado que compromete el voto) y de legitimación social.

Los programas y proyectos urbanos así como la privatización de funciones y servicios públicos, se han convertido en uno de los principales aliados que tienen los gobiernos municipales para el desarrollo de las ciudades y para generar espacios públicos y privados. Estos son manejados por la gestión del gobierno mediante organismos autónomos o formas empresariales que vinculan la cooperación pública con la privada.

El conflicto surge debido a que los agentes privados orientan las intervenciones de acuerdo con sus intereses particulares y el sector público no fija condiciones mínimas que garanticen resultados favorables para el interés colectivo: no hay mediación entre ambas visiones, la pública y la privada, para establecer compromisos equitativos. El sector público se olvida de su función de beneficio para la población independientemente de la clase social a la cual pertenezca, y cede a presiones económicas $\mathrm{y}$ a intereses particulares que orientan las acciones de desarrollo urbano. Lo que ha cambiado con el urbanismo neoliberal es la forma, contenido y objetivo en el modo de construir el espacio público, pero también de usarlo y simbolizarlo (Pradilla, 2009).

Este tema ha sido tratado de forma distinta entre las autoridades interesadas en estudiarlo, que en ocasiones contradicen sus posturas. Autores como Borja (2005) han tenido un papel fundamental en la función pública y en las decisiones políticas, por lo que no es de extrañar que para él:

La presentación de las ciudades como lugares nodales, las nuevas oportunidades de los territorios (argumento apoyado en emergencias y reconversiones exitosas) y la prioridad al posicionamiento en las redes globales y, en consecuencia, a su proyección exterior han sido elementos clave de la construcción del vademécum de la buena política urbana. El plan estratégico, a su vez, ha sido la herramienta operativa (o ha pretendido serlo) de las ciudades aspirantes a triunfar en el mundo global mediante el discurso «hipercompetitivo» (pp.16-17).

En su opinión, el urbanismo neoliberal debe ser encarado como una forma positi- 
va de atraer inversión, de mercantilización de los espacios como, lo ha presentado el modelo Barcelona. Esta postura ha sido importada a varios países de Latinoamérica (Borja, 2005), con consecuencias diversas, ya que por un lado ha aportado puntos interesantes al estudio del espacio público desde un punto de vista más conceptual, pero también se ha implantado con discursos contradictorios, entre la academia y la función pública que impiden tener una visión clara sobre el tema.

Borja \& Forn (1996) creen que el mayor desafío de la planeación urbana contemporánea es aumentar el potencial competitivo de las ciudades en el sentido de responder a las demandas globales y atraer recursos humanos y financieros internacionales. No obstante, de acuerdo con varios ejemplos que hemos observado, el planeamiento se ha hecho al margen de la ciudad, en paralelo con los objetivos del capitalismo neoliberal. Este discurso es similar al del alcalde Garrigós de Cuernavaca, quien magnificaba las intervenciones en el espacio público como forma de regenerar la ciudad y hacerla competitiva. Posteriormente, Borja (2005) reconoció que estos proyectos de renovación urbana se constituyen como proyectos políticos de ciudad y que pueden "derivar en una cortina de humo llena de buenas intenciones sin otra función que legitimar las practicas del poder" (p. 17).

Las políticas, intervenciones e imaginarios de la clase política apuestan a la imagen que pueden crear de la ciudad, lo que representa una negación de los intereses y las necesidades de algunos ciudadanos: los espacios creados por algunas renovaciones urbanas se han concebido al margen de los usuarios, haciendo que no los usen ni generen identidad alguna con ellos. Este tipo de intervenciones, desvinculadas de su contexto territorial y social, parecen reducir los lazos de sociabilidad, de integración social, de no identificación de los habitantes con su entorno y generan, en ocasiones, su abandono: ellos carecen de ciudadanía, porque no producen convivencia, pues se confinan en los espacios privados doméstico o en los centros comerciales. Contrariamente, también existen espacios públicos que siguen vivos, usados, transformados y apropiados por las personas en su quehacer cotidiano, como el parque Cri Cri y la Plazuela del Zacate.

Esta realidad se contrasta con lo que define Augé (2005) de los espacios de tránsito, caracterizados como no lugares, que retoma Carrión (2007), y los considera dentro de las nuevas corrientes de la urbanización en América Latina; la plaza, se dice, ha perdido funcionalidad y, con ello, estamos viviendo su forzosa desaparición. De espacio estructurante ha pasado a ser un espacio estructurado, residual o marginal, incluso ha tendido a desaparecer por la pérdida de sus funciones o por la sustitución por otros espacios más funcionales, en términos de reproducción del capital, como serían para el urbanismo actual el centro comercial o el club social. El autor comenta que cumplen la función de no lugares, pues son solo lugares de paso. En este punto la posición de Carrión (2007) territarias 35 
resulta cuestionable, porque aun siendo de paso esos espacios públicos cumplen otras funciones, además de ser construcciones históricas, de múltiples agentes cambiantes en el devenir del tiempo.

Estos modelos fragmentan socialmente a la ciudad y han tenido un aumento significativo a través de las nuevas formas urbanas que generan e incrementan las desigualdades y disparidades entre la sociedad y las bifurcaciones extremas entre la riqueza y la pobreza (Smith, 2005). Tenemos así una combinación de intereses estimulada por el concepto de city marketing o marketing urbano, que surge de un nuevo sistema de políticas públicas que se adoptó en varias ciudades y que pretende promoverlas a nivel local, regional y global, acorde con bases estratégicas del planeamiento urbano que lo implantan y lo promueven. $\mathrm{Hu}^{-}$ bo un refuerzo de la imagen de vitalidad urbana alcanzado por medio de obras de construcción de nuevas infraestructuras pretenciosas que reconcilian o intentan reconciliar las debilidades y las fragilidades de las ciudades, dentro de una lógica que responde a lo que se definió como sociedad del espectáculo (Debord, 1971).

La diferencia entre las intervenciones realizadas en diferentes ciudades radica en los matices diferenciados que dependen de la historia, de las características de ellas y el entorno en el cual se han desarrollado, a pesar de que la ideología mediante la cual se transforman sea muy similar, y los usos del espacio que cambian la tipología. Aun cuando hablamos de contextos y escalas tan diferentes, existen elementos que unen los espacios y las políticas de intervención: la idealización de lo bello; la tendencia a sacar a los feos y sucios de los espacios centrales o principales de la ciudad; los imaginarios de las clases media y alta; la marca global que se reproduce en todas las ciudades, en lugar de desarrollar una identidad propia a través de la creatividad o de los artistas y la sociedad que trabajan localmente.

Algunos autores tejen fuertes críticas a estas intervenciones de los espacios públicos como Davis (1992), De Mattos (2007), Duhau \& Giglia (2008), Harvey (1989) y Smith (2005); ellos argumentan que la ciudad se vuelve una mercancía para el consumo de pocos al mismo tiempo que excluye a los más desfavorecidos, tal y como se percibió en el centro de Cuernavaca. Por otro lado, algunos autores argumentan que con las intervenciones hechas, la ciudad pierde su significado historicista, los lugares ganan nuevas identidades: los lugares se resignifican, se refuncionalizan, pero no pierden su característica de espacios de lugares como se vio en el centro histórico de la ciudad en la Plaza y los lugares de los trabajadores como el parque Cri Cri.

La refuncionalización y resignificación es consecuencia de procesos dinámicos y dialécticos que se dan al interior de las ciudades, como construcciones efímeras que se disuelven con la acción del mercado y que se van materializando en las ciudades. Los dispositivos de control son cada vez más sutiles y menos evidentes; estos activan este conjunto de principios que tienden a expandirse en todos los espacios, desfiguran lo "nuevo" e influencian las estructuras 
sociales. Nos preguntamos, ¿es esta ciudad, fragmentada y seleccionada por el neoliberalismo para grupos minoritarios y selectos de los ciudadanos y orientada por el mercado capitalista, la que produce y a la que tiene derecho la ciudadanía, y nos hace ciudadanos? ¿Es la que nos da el derecho a la ciudad? ¿A cuál ciudad, nos preguntamos?

\section{3. ¿Cuál derecho y cuál ciudad?}

Dentro del concepto de mercantilismo urbano en la ciudad neoliberal, muchas de las intervenciones que se promueven por los servidores públicos tienen como fundamento lo que se ha llamado el derecho a la ciudad. Este slogan ha ganado muchos adeptos, argumentando que entre más se use la ciudad, se construye más ciudadanía y apropiación de las urbes para beneficio de los más desposeídos, con ello justifican las intervenciones de privatización a pesar de que generen mayores desigualdades entre los usuarios. De ser así, nos preguntamos, ¿de dónde nace este concepto y cómo fue manejado por sus promotores con el fin de probar si el uso del término corresponde al que se le está dando en la actualidad?

En la década del setenta, en Europa, después de la reconstrucción originada por el desastre de la $2^{\text {a }}$ Guerra Mundial y con la importancia que el marxismo tuvo para entender la realidad social del momento, la urbana en particular, Henri Lefebvre, uno de los pensadores de izquierda más renombrados de la época, escribió, ente otros libros, uno que ha sido muy polémico y utilizado en la actualidad titulado el derecho a la ciudad (1973). Se pasaba así del derecho a la vivienda, que se promovió después de esta contienda para reconstruir las ciudades derruidas por la guerra, al de la ciudad, cuando el problema habitacional fue resuelto en aquel continente.

El derecho a la ciudad de Lefebvre es un concepto que, al igual que la producción del espacio (1991), va construyendo a lo largo del libro, ya que no está explícitamente tratado desde el inicio de su exposición, sino que, lo elabora a lo largo de su discurso y lo define hasta el final de texto; ¿cómo es que se desarrolla esta construcción? A partir del uso de herramientas, metodología y categorías marxistas, analiza las condiciones y procesos del fenómeno urbano de los años setenta en Europa, lo que a diferencia de lo que sucede con su uso en la ciudad neoliberal lo sitúa en una postura crítica no solo del capitalismo y de la economía inmobiliaria de ese momento, sino que se opone a posturas teóricas que explicaban la ciudad desde el funcionalismo y la ecología urbana de la Escuela de Chicago, tan en boga en ese momento. La dimensión histórica para analizar el paso de la ciudad precapitalista a la urbanización del momento es otro de los elementos fundamentales que es preciso rescatar y le dan consistencia a su postura crítica. La construcción del proceso lo hace en cuatro instancias que se analizan a continuación.

En primer lugar, el autor se ubica dentro de tendencias de largo y muy complicado alcance: el proceso es analizado a partir del paso de la ciudad-Estado a un sistema urbano mucho más complejo que territarias 35 
está formado por tres dimensiones: la sociedad, el Estado y la ciudad (Lefebvre, 1973), que se forma a partir del binomio industrialización-urbanización. El valor de uso se lo adscribe a la ciudad y el de cambio a la industrialización, motor fundamental para la construcción de la ciudad capitalista (Lefebvre, 1973). De ahí pasa al crecimiento urbano que se empieza a dar cuando las industrias se localizan fuera de las ciudades y agregan que este crecimiento se apodera de la ciudad antigua pero luego la transforma, la deteriora y la fragmenta, pues origina la existencia de diferentes zonas que el funcionalismo urbano extiende y planea. Así la ciudad dividida en zonas es parte del resultado de este crecimiento, y da como resultado "las ciudades y aglomeraciones, ciudades obreras, barrios periféricos que son apéndices donde la industrialización no alcanza a ocupar y fijar la mano de obra disponible" (Lefebvre, 1973, p. 23).

Este es definido como un doble proceso que distingue y analiza a partir de binomios: industrialización y urbanización; crecimiento y desarrollo; producción económica y vida social, aspectos que son inseparables, con cierta unidad pero, según el autor, en conflicto al interior de ellos (Lefebvre, 1973). Estos aspectos se presentan como contradicciones dentro de la ciudad que la acompañan en su transformación.

Especial importancia pone al crecimiento de la aglomeración industrial en donde los suburbios forman parte importante de ella como contornos; se expulsa al proletariado del centro urbano y de la ciudad para llevarlos a las periferias indus- triales, quedando el suburbio para clases medias y altas. En su opinión, esta expulsión destruye la urbanidad, pues ya no están en el centro, lo que descentra a la ciudad al perderse el proletariado de la obra central. El suburbio es considerado como enemigo de la ciudad, ya que es una periferia desurbanizada, pero muy dependiente de la ciudad. Habla entonces de urbanización, desurbanizante y desurbanizada como aspectos importantes del proceso mismo de crecimiento y expansión de las ciudades (Lefebvre, 1973).

Este proceso se amplía hasta formar la megalópolis de la Europa del Norte que se extiende desde el Ruhr hasta el mar del Norte, incluyendo a las ciudades inglesas, y de la región parisina a los países escandinavos (Lefebvre, 1973), conformada a partir de un tejido urbano que cuenta con suburbios integrados, construyendo una red urbana mucho más amplia que abarcaba desde entonces extensiones considerables.

En este contexto de crecimiento ampliado que se genera en el proceso de urbanización, Lefebvre (1973) hace una distinción importante entre hábitat y habitar. Habitar era "[...] participar en una vida social, en la comunidad, pueblo o ciudad, misma que se rompe paulatinamente con el proceso" (p. 32), mientras que el hábitat refiere a una condición en donde se pretendía mejorar la calidad de vida de los trabajadores y se le agregaba el acceso de la propiedad. Con ello se vincula directamente al trabajador con el acceso a la vivienda, que se convierte en una mercancía promovida por el sector inmobiliario que 
prioriza la construcción y desarrollo de barrios autosuficientes y de nuevas ciudades descentradas de las antiguas. Como resultado, dice, surge la vivienda en estas nuevas ciudades como un derecho que asume el servicio público y el Estado como parte de su responsabilidad. Entonces más que preocuparse por generar entornos para habitar en una ciudad, el Estado promueve el derecho a la vivienda y al hábitat como parte fundamental de su actividad social, con orientaciones que favorecen a la economía de mercado, ligándose con el sector inmobiliario. $\mathrm{Al}$ respecto dice:

El derecho al alojamiento aflora, por así decir, en la conciencia social. Se hace reconocer de hecho, en la indignación que los casos dramáticos levantan, en el descontento que la crisis engendra. Sin embargo, no es reconocido formal y prácticamente; es reconocido, por el contrario, como apéndice a los “derechos del hombre (Lefebvre, 1973, p. 35).

Surge una ciudad mutilada, deteriorada y fragmentada, subordinada a la necesidad de construir un hábitat que en las condiciones que lo hace deja de tener condiciones de habitar y que queda organizado en el urbanismo de los hombres de buena voluntad: el de los administradores y el de los promotores que en sus diversas tendencias contribuyen a la construcción de un caos que es difícil detener o contener.

En segundo lugar, es desde esta perspectiva y construcción de la ciudad que el autor la define a través de sus transformaciones particulares y no de las generalizaciones globales ni pasivas. La ciudad depende, dice, “.... de relaciones de inmediatez, de vinculaciones directas entre las personas y grupos que componen la sociedad (familias, cuerpos organizados, oficios y corporaciones, etc.)" (Lefebvre 1973, p. 64), poniendo un punto medio entre las ordenes de relaciones próximas entre los individuos y grupos y las que se llevan a cabo entre ellos y las instituciones como el Estado y la Iglesia que predominan en la ciudad, identificándola como una forma de mediación entre ellas (Lefebvre 1973, p. 64). En este contexto se define la producción de la ciudad ubicándola más que en la producción de objetos urbanos es la producción de relaciones sociales como parte de la producción y reproducción de los seres humanos amplia el concepto de producción a una doble dimensión: la de obras y la de relaciones de producción. Es así que por un lado toma a la ciudad como una totalidad en donde la ciudad es la obra y lo urbano es la realidad social (Lefebvre, 1973), ambas formando parte de un todo.

La relación campo ciudad no la considera exclusivamente como un elemento aleatorio de dependencia entre ambos espacios, sino que la trabaja a partir de tres términos: la ruralidad, el tejido urbano y la centralidad. Más que trabajarla como oposición o relación, la maneja como mediación y, por lo tanto, en esa expansión constante de la ciudad adquiere una dimensión especial a la que le da mucha importancia.

En tercer lugar, para él es fundamental el tema de la crisis de la ciudad, manejada a partir de dos aspectos. El primero tiene que 
ver con las transformaciones que cambian su fisonomía, y el segundo, con su crisis, en su opinión, es una crisis teórica y práctica. En la primera el concepto de ciudad (de la realidad urbana) se compone de hechos, representaciones e imagines tomadas de la ciudad antigua, pero en una nueva elaboración que la caracteriza. En la segunda, que es práctica, el núcleo urbano se resquebraja y continúa desbordado hacia los suburbios, generando y manteniendo su deterioro o descomposición (Lefebvre 1973).

El otro aspecto de la crisis de la ciudad se da por la discontinuidad que se presenta en la urbe contemporánea con los modelos que generaron las anteriores y en donde prevalece una morfología urbana que constituye su forma y contenido: la segregación que se produce al expulsar a las clases proletarias hacia los suburbios que origina una vida cotidiana recortada en fragmentos (Lefebvre, 1973). El resultado es la producción de gettos organizados por grupos sociales afines, zonas en donde estos se reproducen y viven, así como una separación entre ellos y con la sociedad urbana. El consumo es un elemento fundamental que genera esta fragmentación de las ciudades, pues son diversos y diferentes los consumos que se generan a su interior. Agrega que la ciudad está muerta a pesar de que lo urbano este presente, pero es disperso y alienado. Entonces la crisis no solo implica la existencia de discontinuidades económicas al interior de la urbe, sino también políticas, sociales y de otros tipos que generan el rompimiento entre lo urbano y la ciudad.
En cuarto lugar, el autor enfatiza los aspectos fundamentales de la metodología para acercarnos a la ciudad en donde hay que evitar que la morfología urbana y las continuidades o discontinuidades en los procesos sean tratados como elementos absolutos, ni como procesos globales o particulares exclusivamente. Es importante que instituciones y relaciones salgan de situaciones de clase que las definen y las transforman en relaciones personales, locales que son también de orden impersonal o bien de otras que se dan en el plano de lo percibido y lo concebido y son relevantes para comprenderlas.

Es desde estas posturas que el autor desarrolla el derecho a la ciudad, con ello propone el surgimiento de una nueva urbe que tenga bases diferentes a las que el capitalismo generó hasta ese momento. Para ello, dice, es necesario hacer un programa en el que se integre y haga una síntesis o unidad la ciencia de la ciudad, el arte, la técnica del conocimiento. En este debe haber una participación ciudadana como elemento que integre una serie de derechos concretos, no fragmentados los cuales surgen a partir de una gran contradicción de la vida urbana que refiere a la creciente socialización de la sociedad y la segregación generalizada que se produce (Lefebvre, 1973, p. 137) De ahí que aparecen los derechos concretos que materializan los abstractos que tiene la humanidad y el ciudadano; estos forman parte de los pilares de la democracia, entre los cuales se tienen los siguientes: los del hombre y ciudadano que se rigen por 
el principio de la democracia en donde se insertan "los derechos de las edades y los sexos (la mujer, el niño, el anciano), derechos a las condiciones (el proletario, el campesino), derechos a la instrucción y la educación, derecho al trabajo, a la cultura, al reposo, a la salud, al alojamiento.

En suma, el derecho a la ciudad es, en la visión de Lefebvre, una manera de repensar la utopía de futuro de la vida urbana de los citadinos y de los habitantes del campo. También es una manera de integrar la concepción de la ciudad en su totalidad y no dividida en fragmentos como lo hace el funcionalismo y, en la actualidad, el posmodernismo. En esta concepción el autor integra varios aspectos que incluye una forma de vida cotidiana que satisfaga las necesidades y la reproducción de la clase trabajadora que vive en la ciudad, sin restringirse exclusivamente a un espacio en particular, sea este público o privado y mucho menos al uso de alguno de ellos, ni al centro histórico o los espacios públicos de la ciudad. Incluye una manera de ver la generación de hábitats que permitan una vida cotidiana digna de cada uno de los habitantes, accediendo al habitar es decir, a la propiedad y al mejoramiento de las condiciones de vida de los habitantes de la ciudad.

Es a partir de esta definición cuando se encuentran diferencias entre el uso de la categoría de derecho a la ciudad de Lefebvre y la del mercantilismo neoliberal. En el uso del derecho, hemos utilizado el funcionalismo no solo para planear y dividir a la ciudad, sino para fragmentar la manera como la entendemos y nos acercamos a ella: la separación entre lo público y lo privado es una forma de hacerlo. Ahora, más que hablar de ciudad se habla de espacio público al cual se le adscribe la condición de social y de espacio de la cotidianeidad, como si la vivienda y el espacio privado no lo fueran. Además, solo el uso del espacio público es lo que nos da la condición de democratización de la ciudad y el derecho a ella sin que se tome en cuenta las condiciones de vivienda en las que se encuentran los ciudadanos, sin importar las condiciones salariales que estos tienen o el tiempo que tardan en recorrer la ciudad, independientemente que destinen a la movilidad hasta seis horas al día o más, a las que se incluyen las de sus jornadas de trabajo.

Es preciso señalar que hay que agregar una dimensión adicional a la concepción lefebvriana sobre el derecho a la ciudad, pues ahora estamos ante una nueva crisis urbana por la discontinuidad y fragmentación que se ha dado entre la ciudad industrial moderna del siglo XX y la ciudad terciaria del siglo XXI (Ramírez, 2006), en la cual la industrialización ya no es el eje fundamental de su conformación, sino la actividad terciaria y de servicios en una doble dimensión: la producción del servicio y su consumo. Desde esa perspectiva, lo que se toma fragmentariamente como derecho, más que constituir un mejoramiento en la calidad de vida en una forma integral, fragmenta los derechos urbanos, por ello, la vivienda, el descanso y la vida cotidiana se han convertido en valores de cambio que es preciso comprar e intercambiar como mercancías y no forman parte ya 
de la demanda de solución de necesidades básicas resueltas. Desde esta perspectiva, el discurso del derecho a la ciudad inmerso en el neoliberalismo es una construcción ideológica que intenta resolver, minimizar y legitimar la disminución de la calidad de vida que tienen los habitantes de las ciudades, incluyendo la de Cuernavaca, en donde se ubicó nuestro estudio: con esto se justifica la forma mercantil como se reproduce en la actualidad y las acciones que los gobiernos, sean estos de izquierda o de derecha implementan para embellecerla.

$\mathrm{Al}$ manejar esto a partir de las contradicciones que evidencia el autor, constantemente observamos que si bien hay un discurso por obtener el derecho para acceder a una vida cotidiana citadina, parecería que el proceso se encarga de no proporcionarla; por el contrario, entre más lejana se localiza la vivienda en los bordes urbanos, menos calidad de vida se tiene, a pesar de usar y transitar por el espacio público del centro de Cuernavaca o bien del de Plaza Galerías, que es un bien de carácter privado para uso público en el borde de la ciudad.

Es preciso añadir que en esta transición, hay un paso significativo en la intervención del Estado, ya que en la concepción lefebvriana este era una institución fundamental para la generación de una buena parte de los soportes materiales que constituyen la ciudad. En la actualidad, el Estado, sea cual fuere su tendencia, se ha convertido en un gestor de proyectos o de intervenciones urbanísticas tal y como se ejemplificó, que se dedica a mejorar algunos espacios públicos mientras que otros se han privatizado como serían los centros, ambos construidos por el impulso y el beneplácito estatal.

Cabe destacar que si bien Lefebvre le da una importancia fundamental a la centralidad como eje rector de la organización de la ciudad, en su producción y generación acepta la constitución de otras centralidades mientras sirvan para la convivencia cotidiana y un mejoramiento de la vida ciudadana. No restringe la centralidad al centro histórico como ahora se ha promovido, pero presenta condiciones para que otras se generen. Lamentablemente esto se ha hecho a partir de los centros comerciales privados que generan espacios seguros para el esparcimiento de las personas, adscritas a las clases sociales que pueden acceder a ellos.

\section{Reflexiones finales}

En el presente trabajo, queda manifiesto que ha habido un uso fragmentario del concepto de derecho a la ciudad que Lefebvre, en su momento, construyó para hablar de la necesidad de eliminar el funcionalismo de la planeación urbana y retomar elementos de derecho a la calidad de vida que los habitantes requerían para su sustento. Es evidente que en los planteamientos como los que hacen Borja (2005) y sus seguidores, en relación con las ciudades europeas, usan elementos funcionalistas que pretendían erradicar de la propuesta; ellos argumentan que el espacio público mercantilista y neoliberal es el que resolverá la fragmentación, pero lo que es peor, sirven como inspiración para proponer los 
cambios de las ciudades latinoamericanas, esperando con ello generar ciudadanos e imponer gobernanza en donde ya no la hay.

En América Latina el planteamiento incluso ha ido más lejos. De acuerdo con la concepción de Segovia \& Jordán (2005), quienes trabajan para la Cepal, el concepto de espacio público refiere a un espacio social o a uno de cotidianeidad, a pesar de que este carece de definición sobre espacio público. Se inserta en la globalización, pero se le caracteriza como segregado, carente totalmente de contexto para definirlos como modernos, feos o sucios. Sin duda que es la apariencia la que define esta caracterización. El espacio público es percibido como una amenaza por la inseguridad que presenta. Con ello, se asume que todos los problemas relacionados con este tema se dan en el espacio público, lo que es limitante y podríamos afirmar que hasta erróneo: es el espacio que genera temor y miedo dejando de lado el contexto actual en el que está inserto. El refugio a estas presiones son en los espacios privados que se construyen ahora, como las casas enrejadas, los barrios cerrados y los suburbios alejados (Segovia \& Jordán, 2005).

En esta concepción, el espacio público es manejado homogéneamente, de la misma manera y en todas las realidades sociales, pero a su vez se le asume como un espacio de la interacción social en donde se construye la identidad colectiva. Si se pierde esta identidad, aumenta la inseguridad. Hace un paso entre el espacio público y la pobreza sin mediaciones, pues la cercanía generada por las redes de cooperación y de seguridad que se dan en el espacio público pueden ayudar a eliminar la pobreza, como si en automático con identidad, seguridad y espacio público la pobreza del continente pudiera ser eliminada, ya que se afirma que la convivencia del espacio público resuelve la pobreza, pero también la inseguridad (Segovia \& Jordán, 2005).

Las dualidades entre el espacio público y el privado, las consideraciones del derecho a la ciudad como ideología para justificar la acción estatal y otras que han sido analizadas anteriormente son limitantes para poder entender el espacio en una perspectiva más amplia. La multidimensionalidad que los espacios tienen y las múltiples posibilidades de producción, interpretación, uso, transformación, apropiación y construcción (Massey, 2005) quedan fuera de las visiones que se tienen para interpretarlas, por ello, la riqueza de las experiencias que se presentan en los espacios, sean públicos o privados, son eliminadas de los análisis de la realidad que presentamos.

\section{Referencias}

Augé, M. (2005). Não-Lugares. Introdução a uma Antropologia da Sobremodernidade. Lisboa: 90 Graus Editora.

Bauman, Z. (2005). Liquid Life. Cambridge: Polity.

Borja, J. (2005). Revolución y contrarevolución en la ciudad global. En D. Harvey \& N. Smith. Capital financiero, propiedad inmobiliaria y cultura (pp. 9-27). Universitat Autónoma de Barcelona, MACBA. Barcelona. 
Borja, J. \& Forn, M. (1996). Políticas da Europa e dos Estados para as Cidades. Espaço e Debates, 39, 32-47.

Brenner, N. \& Theodore, N. (Eds). (2002). Spaces of neoliberalism: urban restructuring in Western Europe and North America. Boston: Oxford, Blackwell.

Caprón, G. (1997). Urbanidad y modernización del comercio: Un análisis a partir del caso de los shopping centers en Buenos Aires, VI Encuentro de Geógrafos de América Latina: Territorio en Redefinición. Lugar y Mundo en América Latina, Instituto de Geografía, Facultad de Filosofía y Letras, Universidad de Buenos Aires.

Carlos, A. F. (2001). Espaço-Tempo na Metrópole: a fragmentação da vida cotidiana. São Paulo: Contexto.

Carrión, F. (2007). Espacio público: punto de partida para la alteridad. En O. Segovia (Ed.). Espacios públicos y construcción social. Hacía un ejercicio de ciudadanía (pp. 79-97). Santiago de Chile: Ediciones SUR.

Castells, M. (1996). The rise of the network society. Cambridge: Blackweel Publishers.

CEPAL. (2014). Pactos para la igualdad: bacia un futuro sostenible. Santiago de Chile: CEPAL

Cornejo, I. (septiembre de 2006). El Centro Comercial: ¿una nueva forma de "estar juntos"? Cultura y representaciones sociales, año 1 (1) (YCl), 93-127.

Cornejo, I. (2007). El lugar de los encuentros, comunicación y cultura en un centro territarias 35 56
Davis, M. (1992). Planeta de ciudades miseria. Madrid: Foca.

De Mattos, C. (2007). Globalización, negocios inmobiliarios y transformación urbana. Revista Nueva Sociedad, 82-96 Recuperado el 21 de 09 de 2012, de: N.212 [YCl]. http://nuso.org/media/articles/downloads/3481_1.pdf

Delgado, M. (2011). El espacio público como ideología. Madrid: Catarata.

Duhau, E. \& Giglia, Á. (2008). Las reglas del desorden: habitar la metrópoli. México: UAM- Azcapotzalco y Siglo XXI.

Estévez, B. (2012). La idea de espacio público en geografía humana. Hacia una conceptualización (critica) contemporánea. Documents d'Anàlisi Geogràfica, $58(1), 137-163$.

Harvey, D. (1989). The Urban Experience. Oxford: Basil Blackweel.

Harvey, D. (2004). The Urban Process under Capitalims: A framework for Analysis. En G. Bridge \& S. Watson. The Blackwell City Reader. Malden: WileyBlackwell

Hiernaux-Nicolas, D. (2000). "El reencantamiento de los espacios de consumo en las ciudades", IV Encuentro Ciudades y Culturas Contemporáneas. Ciudad de México: ENAH

Lefebvre, H. (1973) [1969]. El derecho a la ciudad (2 ${ }^{\mathrm{a}}$ Ed.). Barcelona: Ediciones Península.

Lefebvre, H. (1991). The production of space. Oxford: Blackwell.

López Levi, L. (agosto de1997). Los centros comerciales como espacios multifuncionales. Argumentos, (27), 81-96. 
Massey, D. (2005). La filosofía y la política de la espacialidad: algunas consideraciones. En L. Arfuch (Comp.), Pensar este tiempo: espacios, afectos, pertenencias (pp. 101-128). Buenos Aires: Paidós.

Narciso, C. (2014). ¿Cuál Espacio Público? Los lugares de uso, consumo y diferenciación social en la Ciudad de Cuernavaca. Tesis de Doctorado en Urbanismo, México, Universidad Nacional Autónoma de México, Facultad de Arquitectura, Posgrado en Urbanismo.

Portas, N. (2003). Espaço Público e cidade emergente. En P. Brandão \& A. Remesar, Design e Espaço Público, deslocação e proximidade (pp. 16-25). Lisboa: Centro Portugues de Design.

Pradilla, E. (2009). Los territorios del neoliberalismo en América Latina. México: UAM-X, Miguel Ángel Porrúa.

Ramírez Kuri, P. (1993). Transformaciones espaciales y modernización urbana: la Ciudad de México y los macro-proyectos comerciales. Centro Comercial Coyoacán (1989-1993). Tesis de Maestría en Estudios Regionales. México: Instituto de Investigaciones Dr. José María Luis Mora.
Ramírez Kuri, P. (2009). Espacio público y ciudadania en la ciudad de México. Percepciones, apropiaciones y prácticas sociales en Coyoacán y su centro histórico. México: UNAM-IIS. PUEC, Miguel Ángel Porrea.

Ramírez, B. (2006). Del Funcionalismo industrial al funcionalismo de servicios: ¿una nueva utopía de la metrópoli postindustrial del Valle de México? EURE, XXXII (95), 61-74.

Segovia, O. \& Jordán, R. (2005). Espacios públicos urbanos, pobreza y construcción social. Santiago de Chile: CEPAL, Naciones Unidas, División de Desarrollo Sostenible y Asentamientos Humanos, Medio Ambiente y Desarrollo, serie 122.

Sennett, R. (1978). El declive del hombre público. Barcelona: Anagrama.

Smith, N. (2005). Capital financiero, propiedad inmobiliaria y cultura. En D. Harvey \& N. Smith, Capital financiero, propiedad inmobiliaria y cultura (pp. 59-78). Barcelona: Universitat Autónoma de Barcelona, MACBA. 
